\title{
ANIMALES TRANSGÉNICOS COMO ORGANISMOS ARTIFICIALES
}

\begin{abstract}
Alexandre Bota Arqué*
Resumen: La modificación genética de organismos vivos ha generado interrogantes éticos de difícil solución. La búsqueda de marcos conceptuales lleva a plantear si ha habido una modificación del estatuto ontológico de los organismos alterados por la biotecnología. Este artículo realiza una aproximación al organismo biotecnológico a partir del pensamiento de los filósofos José Ortega y Gasset y Xavier Zubiri acerca del hombre y de la técnica, conceptualizando el objeto artificial biotecnológico como "organismo artificial", con la particularidad de ser el primer objeto producido por el hombre que se reproduce independientemente.
\end{abstract}

Palabras clave: biotecnología, bioética, OGM

\section{TRANSGENIC ANIMALS AS ARTIFICIAL ORGANISMS}

Abstract: The possibility of genetic modification of living organisms has generated ethical questions of difficult solution. The searching for conceptual frames has put into question whether the ontological status of organisms altered by biotechnology has been changed. This paper approaches the biotechnological organism following the thinking of philosophers Ortega y Gasset and Xavier Zubiri, based on their view on anthropology and technology conceptualizing the biotechnological artificial object as an "artificial organism" with the particularity that it is the first object produced by human beings which reproduces independently.

Key words: biotechnology, bioethics, genetically modified organisms

\section{ANIMAIS TRANSGÊNICOS COMO ORGANISMOS ARTIFICIAIS}

Resumo: A modificação genética de organismos vivos gerou interrogativos éticos de difícil solução. A busca de marcos conceituais leva a questionar se ocorreu uma modificação do estatuto ontológico dos organismos modificados pela biotecnologia. Este artigo realiza uma aproximação ao organismo biotecnológico a partir do pensamento dos filósofos José Ortega y Gasset e Xavier Zubiri a respeito do homem e da técnica. Conceptualiza o objeto artificial biotecnológico como um "organismo artificial", com a particularidade de ser o primeiro objeto produzido pelo homem que se reproduz independentemente.

Palavras chave: biotecnologia, bioética, OGM

* Instituto de Tecnoética de Barcelona, España

Correspondencia: alexbota@fundacion-epson.es 
El organismo genéticamente modificado (OGM) es el producto de un proceso natural y de la intervención del humano. Pero, ¿qué es este ser humano?

\section{Homo sapiens, entorno natural y entorno artificial}

El homo sapiens se puede definir a partir de diferentes aproximaciones. Una de ellas, que a mi entender es reveladora, es su capacidad de proyección. Él no se sitúa en el medio en una relación receptora de estímulos sino como realidad; no sobrevive adaptándose al medio sino adaptando el medio a sus necesidades. Esta transformación es realizada mediante la techne, generando un entorno artificial. ¿Cuándo el humano o el primate empezaron a generar el entorno artificial?

Durante siglos los hombres han fundamentado la distinción respecto de los demás animales en un famoso pensamiento de Aristóteles: el hombre es el único animal que tiene logos. Zubiri afirma que esta definición ha llevado al hombre por unos derroteros improductivos en la tarea de entenderse y entender a los animales. Definirá al hombre como un animal que se sitúa en la realidad, no en una relación estímulorespuesta, sino en términos de una inteligencia sentiente. Si Zubiri hubiera podido asignar el nombre del primer homínido, el cual se consideraba humano, seguramente en lugar de Homo sapiens lo hubiera llamado Homo realitas, no como hombre real, sino como "situado en" la realidad. Lo más primario en la intelección no es forjar ideas sino entender la realidad como real.

Generalmente, cuando se han estudiado los contenidos específicos dados al sentir, se olvida que lo sentido es siempre sentido. El proceso fisicoquímico del sentir del hombre y el animal es idéntico y el contenido sensible completamente análogo. Las diferencias más importantes son que el animal responde a estímulos y el hombre a realidades. El estímulo todo, objetivo para el animal, lo encierra en la estimulidad, ya que el estímulo se agota en su función de estimular. La diferencia de un viviente con el humano sólo se puede establecer en el plano del proceso de formalización del estímulo: el humano hiperformaliza alguna de estas informaciones, posiblemente porque no posee mecanismos para dar respuesta a todas las suscitaciones generadas como consecuencia del dinamismo propio de la naturaleza. Esto obliga a que, en algunos casos, el humano tenga que apoderarse de las respuestas y esta apropiación de las posibilidades la deba realizar mediante su inteligencia sentiente, en la cual intervienen el sentir y el inteligir.

El hombre, al poseer una inteligencia sentiente, se sitúa en la realidad de una manera abierta y no encerrado en su entorno. Los dispositivos biológicos del animal le permiten moverse entre los estímulos de un modo rico y variado, mientras que el hombre aprehende las cosas para poder enfrentarse a ellas como realidades, trasciende al estímulo situándose en la realidad: proyecta.

Esta naturaleza innata, o esta deficiencia que provoca que el hombre se proyecte en sus actos, tiene como consecuencia que transforme su entorno no de manera azarosa, ni innata, sino como fruto de un conocimiento que se acumula en el acervo cultural de la humanidad. Las consecuencias de estas transformaciones son los objetos artificiales, la domesticación de las especies y la alteración voluntaria de la naturaleza.

Antes de que apareciese la ciencia o el conocimiento científico, el hombre era técnico. Como diría Ortega y Gasset, el hombre es un ser sin hábitat y necesitado de construir su propio entorno, lo que tiene un gran parecido con la formulación de Zubiri. No hay vida humana 
que no utilice la técnica; la artificialidad es principal en el hombre y lo diferencia de los otros animales que se mueven en lo natural. La técnica va incrementándose paulatinamente sin intencionalidad, por descubrimientos de nuevos mecanismos que responden a los intereses y sueños del hombre: desde hacer fuego a construir una central nuclear. Crear no es dar realidad a las ideas, sino justamente lo contrario: dar ideas a la realidad No hay una intencionalidad consciente en la evolución más allá de la apropiación de posibilidades. Se va generando un crecimiento en la acción del hombre en la realidad, que también va acarreando un incremento del número de objetos artificiales que el hombre produce. De las hachas de sílex a las terracotas, la orfebrería, la vestimenta y las computadoras.

Actualmente, podemos decir que la realidad que se encuentra enfrente de nosotros -esa que no ha interaccionado con la capacidad proyectiva del hombre, la realidad natural- es increíblemente reducida. "Aquello que se reproduce a sí mismo, por sí mismo y sin causa exterior dominante", esa realidad se halla transformada por la techne humana de manera tan profunda que posiblemente ni esta sentencia sea útil en la actualidad. El término "naturaleza" se debe ampliar si esta capacidad proyectiva del hombre es parte de su ser.

Podríamos afirmar que lo artificial es lo natural en el hombre, pues es su signo distintivo respecto del resto de los animales. Es la naturaleza del hombre transformar el medio, no adaptarse ni utilizar. Transformar lo natural es la sedimentación de las invenciones sociotécnicas que se aceptan como recursos dados inmediatamente por una comunidad olvidando su origen; es propia de la especie. Lo que tiene unas implicaciones ontológicas importantes, ya que el objeto artificial -fruto de la técnica- ha sido separado del objeto natural.
La técnica es -junto con el lenguaje- una de las respuestas sociales e intelectuales más complejas que la humanidad ha generado. Con la técnica el hombre pretende liberarse de las fluctuaciones del medio e incrementar su independencia del entorno natural, entorno azaroso o aleatorio. En algunas culturas este proceso de independización lo ha llevado a crear un entorno artificial.

Según Ortega y Gasset, el vivir del hombre no se circunscribe a las necesidades biológicas, sino que se amplía a sus necesidades más superfluas. En el hombre sólo es necesario lo objetivamente superfluo: lo que supera lo necesario. La técnica libera al hombre para que no esté sujeto a las variaciones de la naturaleza; por esto a la técnica le es prefijada una finalidad en su inicio, pero las necesidades del hombre son personales.

Es necesario entender la técnica como una necesidad del hombre: la técnica es natural en el hombre, es vida humana. El error reside en pensar que ella nos ha liberado de la realidad al habernos independizado de la naturaleza, olvidando que el estar abiertos a la realidad es lo que ha permitido desarrollar la técnica. El hombre ha estado abierto a la realidad no únicamente como posibilidad sino como realización. La técnica es la invención de un procedimiento para desarrollar esa apertura, para que así el hombre pudiese apropiarse de las posibilidades. Realizarse en lo superfluo, porque lo necesario se satisface en el nivel estímulo-respuesta; lo artificial es lo natural en el hombre, pero sólo para el hombre.

Pero la técnica, entendida como necesidad del hombre, no tiene raíces como las que puede tener la sophia respecto la naturaleza, sino que depende del programa y de las pretensiones vitales que están en su base. La técnica es una necesidad vital y no todos los hombres tienen 
las mismas. Siendo así, no puede orientar al hombre y el fruto de esta técnica sólo tiene sentido cuando se conoce su utilidad.

A lo largo de la historia la distinción entre objeto artificial y objeto natural ha sido variable. Aunque generalmente se define naturaleza por oposición a lo no natural, el ser natural queda extrínsecamente definido por su oposición al ente que produce el hombre. El objeto artificial es la realización de una idea que no está en la materia misma, sino en la mente del artífice y, por tanto, aunque eso sea una realidad, no es un ser natural, sino artificial. Aunque esté constituido por elementos naturales, este objeto no es natural, es la plasmación de un deseo del hombre.

Como hemos hipotetizado, el hombre, en mayor o menor medida, pretende independizarse de las fluctuaciones del entorno y esto lo hace situarse en un ambiente más o menos artificial: la construcción de casas, el almacenamiento del grano, las prácticas agrícolas, la alfarería, los sistemas de aire acondicionado, por ejemplo. El entorno artificial le permite regular el sistema.

Los vivientes configuran sistemas complejos que van regulándose y mitigando las fluctuaciones azarosas del entorno. Pero en el humano este proceso es proyectado y buscado, no es fruto de la selección natural. Un bonito jardín mantiene más estable la temperatura que un desierto de piedras; un buen arquitecto diseña una casa para aprovechar el fresco en verano y el calor solar en invierno, pero, además, incorpora sistemas de climatización. Un agrónomo modifica un vegetal para que no sufra las heladas nocturnas, mientras que un médico vacuna al paciente para que no padezca la enfermedad.

El entorno artificial responde a una proyección previa. Puede que los primeros Homo sapiens supieran biológicamente construir una guarida, pero en la actualidad la recuperación del instinto es socialmente imposible, si existiese. La artificialidad, fruto de la capacidad proyectiva del hombre, le sirve para apoderarse de las posibilidades e ir generando un nuevo entorno distinguible del entorno natural. Cualquier ser humano podría clasificar los objetos de su entorno entre naturales o artificiales, aun sin conocer su función. Cualquiera podría reconocer lo artificial con un grado de certeza elevado. Además, en el pasado y en algunas culturas, la artificialidad afectaba únicamente a una parte de la cotidianeidad: la transformación del entorno era limitada y la independencia mucho menor que ahora.

Las diferentes comunidades humanas han ido viviendo con diferentes grados de artificialidad, lo que ha implicado que los individuos se hayan estructurado diferentemente en su relación consigo mismos, con los otros, con la artificialidad y con la naturaleza; en estos cuatro ámbitos han ido codeterminando su expresión social y su sentirse ligados a la realidad y al otro. La desestructuración en cualquiera de estos ámbitos provoca un desequilibrio al que el sujeto debe responder.

El viviente es un sistema termodinámico abierto e independiente que intercambia materia, energía e información con el entorno. No se puede entender el viviente como unidad aislada y el humano está interrelacionado con los otros y con su realidad.

Estos cuatro ámbitos conforman el cosmos en continuo dinamismo, afectando permanentemente al humano, el cual tendrá que aprehender los estímulos y apropiarse de la respuesta. Pero, previo a la apropiación, ha de haber un "empoderamiento", entendido como la habilidad para ganar comprensión y control sobre las fuerzas personales, sociales, económicas y políticas, en orden a actuar para mejorar su situación. Ello implica que el humano tendrá que asumir 
las consecuencias, ya que habrá proyectado en función de sus intereses, deseos, sueños. Al existir una apropiación, el acto será un asunto moral del hombre, ya que la respuesta habrá sido escogida para dar respuesta a sus deseos y necesidades. Al elaborar el objeto artificial, el hombre asume sus consecuencias.

El desequilibrio al cual se tendrá que dar respuesta también puede afectar a la sociedad, tanto por problemas internos (desestructuración social) como por externos (desequilibrio ecológico o entre sociedades). Equilibrio no significa que todos los ámbitos posean el mismo peso, sino que en el dinamismo propio del sujeto éstos presenten una metaestabilidad. Frente a estas alteraciones sociales y ecológicas el hombre debe dar una respuesta colectiva y empoderarse colectivamente.

La realidad natural está siendo alejada del contacto directo con el hombre mediante la creación de un entorno artificial que aporta una mayor independencia de las fluctuaciones. Se regula la temperatura de un edificio durante todo el año, se pueden comer frutos de cualquier estación en cualquier momento, se viaja a velocidades animalmente inconcebibles, se observa lo que la televisión genera, contemplándose más el televisor que la naturaleza, por ejemplo. En la actualidad, sobre todo en las sociedades occidentales, la artificialidad ha llegado a todos los ámbitos. Muchos ciudadanos de los países industrializados se relacionan mayoritariamente con la artificialidad. La naturaleza, como entorno que suscita al hombre, ha muerto y sólo se le presta atención cuando sus oscilaciones producen catástrofes (huracanes, terremotos) o cuando el accionar irracional del hombre desestabiliza los ecosistemas con acciones agresivas, lo cual supera la capacidad del sistema artificial de contener la fluctuación o la capacidad de la naturaleza para recobrar su equilibrio.

La artificialidad rebaja las fluctuaciones de la naturaleza que el hombre percibe. Parafraseando a Marx, podríamos decir que la naturaleza sin más sólo puede existir "en unas cuantas islas coralíferas australianas de reciente formación", aunque hasta en esas islas las consecuencias planetarias del accionar del hombre pueden ser constatadas. Gracias a la técnica, el hombre ha creado sus propios objetos conformando su propio entorno. La artificialidad es su membrana con la naturaleza, es el hábitat del hombre, no del homo, y es artificial porque ha sido proyectada a la vista de sus deseos.

En el pasado, este mundo artificial, que colisionaba con la realidad natural, necesitaba del hombre para reproducirse. Hasta ese momento las modificaciones al hábitat eran meramente físicas: el hombre creaba una mesa, un libro o un coche, pero estos objetos necesitaban de la intervención del hombre para reproducirse, eran incapaces de alejarse de su creador; posiblemente porque las modificaciones eran sobre realidad física no viva, es decir, que no podía independizarse. La intervención más agresiva que el hombre podía hacer a la realidad viva era el injerto y la selección forzada, que realizaban tanto ganaderos como campesinos. Pero esto podría interpretarse como una perturbación del sistema, ya que cuando ésta desaparecía el sistema retornaba a su estado de equilibrio, necesitaba del hombre para perpetuarse en todas sus potencialidades.

A partir de la revolución biotecnológica, este entorno artificial que el hombre occidental había ido creando, que le había aportado una gran independencia de las fluctuaciones de la naturaleza, se puede independizar. Ya no necesitará de él para perpetuarse. La artificialidad se reproducirá por sí misma e interactuará con la naturaleza.

Hasta hoy parecía que la escritura era la única creación del hombre que se había independizado y que había empezado a reproducirse, es decir, se escribía sobre lo escrito y 
no sólo sobre lo vivido, sentido o pensado. La escritura es una creación artificial del hombre que pretende reflejar el habla, pero que se ha desgajado, en parte, y se está reproduciendo gracias a los sistemas de impresión hasta hacer casi desaparecer, según Jacques Derrida, gran parte de la cultura oral de muchas comunidades. Pero esta escritura necesita aún del hombre para reproducirse, para evolucionar.

\section{Objeto artificial u organismo artificial}

Hasta hace unos pocos años cualquier persona sin conocimientos podía identificar los objetos artificiales y distinguirlos de los naturales. Las reglas a priori del entendimiento debieran permitirnos reconocer al objeto artificial biotecnológico, pero éste sólo es identificable desde una visión científica. No hay conceptos ni normas a priori que sirvan para entender el sentido ontológico del objeto biotecnológico, del organismo genéticamente modificado (OGM): se necesita otra visión filosófica.

Las modificaciones de la biotecnología de última generación afectan al código genético de los organismos vivos, los cuales se reproducen independientemente del hombre. El objeto artificial, que antes necesitaba del hombre para reproducirse, ahora se reproduce independientemente. Este nuevo objeto artificial pasa a ser un "organismo artificial".

El organismo no es sustancia sino estructura. Al ser modificada parte de su estructura íntima por el hombre, aunque se reproduzca por sí solo -como decíamos de los objetos naturales- no será objeto natural sino organismo artificial. Ni bueno ni malo: organismo artificial proyectado y que responde a deseos del hombre. Flores de colores increíbles, más aromáticas; frutas con múltiples sabores; animales resistentes que no produzcan alergias o que produzcan carnes más sabrosas, etc.
Ese organismo artificial dará de sí indistinguiblemente de los organismos naturales. Pero ese dar de sí -expresión de su actividad- no será fruto de su propia evolución, de la selección natural de las respuestas estimúlicas acumuladas durante generaciones y generaciones, sino de un diseño previo, proyectado por el hombre.

No sólo se instrumentaliza a los vivientes sino que se confunden los discursos, ya que se habla en términos de dos paradigmas inconmensurables: el proceso evolutivo de las especies sujetas a la evolución del entorno y las modificaciones irreversibles de las especies que dan sólo respuesta a los deseos del hombre. Algunos genetistas señalan que únicamente se ha forzado un proceso natural y otros grupos sociales entienden que se ha superado la naturalidad de la presión.

\section{El organismo artificial y sus retos éticos}

Cualquier persona que trabaje en un laboratorio de biología molecular o genética dirá que no hay ningún problema ético en la producción de bacterias o levaduras modificadas genéticamente: no suponen ningún desafío ético relevante más allá de los de bioseguridad. Al momento de surgir estas tecnologías se propuso una moratoria de las técnicas donde se instaba a aplazar voluntariamente una serie de experimentos, proceso que terminó con las recomendaciones de Asilomar ${ }^{1}$.

Los retos éticos que abren los animales GM son poliédricos, ya que en investigación y producción de compuestos de uso médico la utilización de los animales genéticamente modificados es aceptada mayoritariamente, siempre y cuando se cumplan unas normativas

1 Un resumen de los principios que guían las recomendaciones y conclusiones de la Conferencia de Asilomar puede encontrarse en López Moratalla N, (edit.) Deontología Biológica. Pamplona: Facultad de Ciencias de la Universidad de Navarra; 1987: 319-326. 
de manipulación y trato. Pero cuando estos OGM están diseñados para producir una carne más sabrosa las reticencias crecen y cuando se crean OGM de animales de compañía las dudas éticas se incrementan.

\section{Instrumentalización de los animales}

Para muchos investigadores ${ }^{2}$ los problemas éticos de las modificaciones genéticas irreversibles a animales invertebrados son inexistentes: la respuesta será bastante similar y las dudas se reducirán principalmente a los problemas de bioseguridad. Las dudas aparecen cuando se plantean modificaciones en vertebrados y en los casos de animales más cercanos a la filogenia humana.

Aun sin conocer cómo los animales captan la realidad, las modificaciones genéticas en póngidos seguramente generarán más controversia que las que se pudieran realizar en sapos o serpientes. La mera observación de las conductas de los gorilas generará sorpresa sobre la existencia de modelos de comportamiento social muy parecidos a los humanos. Puede que, dentro de unos años, las sociedades se avergonzarán del trato dado a algunos animales. Es importante recalcar todas las mejoras éticas en las temáticas de manipulación, trato y experimentación con animales, y el gran trabajo que están haciendo algunos bioterios. La Declaración Universal de los Derechos Humanos expresa que el hombre es un fin en sí mismo y su alteración es inconcebible, pero, ¿qué derecho tenemos de modificar a los animales?

2 En la práctica, en la totalidad de las publicaciones en las cuales se informan modificaciones genéticas en bacterias y levaduras no se encuentran referencias éticas, lo cual da información indirecta sobre la percepción que tienen los investigadores del problema.

\section{Instrumentalización de la tecnología para responder a deseos}

No existen tecnologías libres de riesgo y la biotecnología es un claro exponente de esto. La producción de OGM para responder a deseos tales como tener peces fluorescentes para ofrecer por Internet provoca la trivialización de una tecnología y la asunción de riesgos globales con unos beneficios más que dudosos. Si por alguna razón el transgén introducido se diseminara, aun sin presentar de momento efectos nocivos, ¿quién sería responsable de descontaminar? Al ser una mascota y no estar destinada a la alimentación, la FDA consideró que su fiscalización no era de su incumbencia, situación que ha dado lugar al desarrollo ahora de un gato hipoalergénico por parte de una compañía de mascotas.

Los organismos genéticamente modificados $\mathrm{y}$, más concretamente, los destinados a la alimentación deben ser cuidadosamente manipulados y controlados. Ahora se introducen animales transgénicos sin ningún control con la única justificación de que hay millones de personas que podrán disfrutar de un animal de compañía. Resulta sorprendente, al menos, esta laxitud regulativa y de liberación de estos organismos. Se puede defender la libertad investigativa, pero también debe haber límites a esta libertad, ya que, muchas veces, no es el propio investigador el que decide qué investigar, sino que se investiga porque se descubre un nicho de negocios.

\section{El organismo artificial y las culturas no tecnocientíficas}

La biotecnología de última generación o biotecnología del ADN recombinante ha generado un nuevo escenario en el cual el organismo/objeto artificial o el objeto/organismo natural son indistinguibles. Nadie es capaz de diferenciar un organismo natural de un orga- 
nismo transgénico si no dispone de un conocimiento tecnocientífico. Un OGM sólo puede ser detectado mediante complicados análisis de laboratorio. Esto implica que su artificialidad es para un reducido número de sujetos, el resto de la humanidad tendrá que vivir confiando ciegamente en las aseveraciones de éstos.

El hombre ha modificado la intimidad de algunos vivientes condicionando enormemente el futuro de éstos. Esta alteración la ha realizado desde una perspectiva antropocéntrica, para dar respuesta a sus deseos individuales -nunca globales-y usando una simbolización concreta de la naturaleza. Sin embargo, no todas las culturas tienen la misma concepción sobre lo que son y representan los diferentes vivientes de la naturaleza. ¿Quién posee la autoridad para modificar íntimamente algo que para otra cultura posee otra simbolización? ¿Cuántos científicos occidentales pueden trascender su visión de la realidad para entender que un animal posee un componente sagrado, o sea, que es un ser con ciertos derechos?

No existe cuestionamiento ético de esta neogénesis de vivientes y debe asumirse que es igualmente una expresión de estos deseos la generación de un ratón Knock-out, que se utilizará como modelo de comprensión de alguna patología, como la creación de peces flluorescentes para los acuarios. No se pretende culpar al deseo humano, sino insistir en que deben existir estructuras de control sobre lo que se realiza en animales. Y más respetuoso se debe ser cuanto más se asemejen a los humanos, porque no se puede definir perfectamente en qué momento se supera la relación estimúlica con la realidad.

Si el deseo del hombre individual es casi ilimitado, los deseos de la humanidad son inconmensurables. ¿Quién podrá utilizar esta tecnología? ¿Quién podrá satisfacer los deseos? ¿Es factible dar un acceso generalizado a estas tecnologías y que éstas se desenvuelvan en un entorno respetuoso con las diferentes culturas, ecosistemas y deseos? Si se produce una liberación masiva de OGM, ¿quién será el responsable del control de la contaminación?

\section{Conclusión}

La idea de entender el objeto biotecnológico como organismo que responde a los deseos del hombre puede ser reveladora, aun sin conocer el sustento ontológico. Desde esta concepción se puede iniciar la reflexión bioética, en la cual se deberá ser muy cuidadoso con todas las concepciones sobre lo que son los vivientes y no realizar las discusiones desde la órbita tecnocientífica. Posiblemente, el primer paso que tendrían que dar los científicos antes de producir nuevos OGM es intentar entender qué otras visiones hay de la naturaleza en las diferentes culturas, y sólo luego empezar a cuestionarse su propia visión.

La biotecnología es una herramienta que genera grandes retos, aunque no por ello debe ser prohibida. Entender el objeto biotecnológico como un organismo dinámico y artificial obliga a ser muy cuidadoso con su incorporación a cualquier ecosistema. Ya que, por primera vez, estos objetos artificiales se reproducirán por sí mismos con consecuencias imprevisibles.

Cuando se elabora una reflexión sobre los objetos creados por una nueva tecnología y la tecnología en sí es necesario utilizar la realidad como plataforma de evaluación y alejarla sustancialmente del marco teórico, para evitar una ideologización del discurso. Pero, en ausencia de un marco filosófico claramente definido, puede ser interesante dialogar con la experiencia de la bioética clínica, utilizando su bagaje histórico y asumiendo que no es más que un punto de partida de un nuevo camino que debe realizar la bioética implicada en los temas de biotec- 
nología y biodiversidad. Y la simplificación de la historia de la clínica se podría resumir en los cuatro principios: justicia, no-maleficencia, autonomía, beneficencia.

\section{Justicia}

La generalización de la biotecnología es tan utópica como la relativa a los niveles de consumo de EE.UU. en el mundo. Entonces, es importante considerar que la respuesta a los deseos de una minoría afectará a toda la humanidad. La realidad en la cual el hombre se sitúa está siendo radicalmente modificada por una parte reducida de la humanidad, pero, a su vez, los organismos artificiales (actualmente los animales están confinados en laboratorios) poco a poco irán saliendo de los límites y terminarán interactuando con la naturaleza dando lugar a otras modificaciones no previstas. Lo único que se sabe es que son mayoritariamente desconocidas. Al ser tan asimétrico, el desarrollo de la biotecnología está incrementando la brecha entre los países de norte y del sur, como se constata en la nula presencia de empresas latinoamericanas en el boom biotecnológico. En resumen, no se puede pretender que un sistema fundado en las patentes y en el beneficio capitalista promueva la justicia social.

\section{No-maleficencia}

Todos estos cambios están siendo vigilados más o menos cuidadosamente. Parece inevitable aceptar que ya son cambios globales en una de las estructuras de la materia viva, su código genético, y es necesario que se creen los espacios para discutir y decidir. El gran problema de la biotecnología es que está guiada por la racionalidad tecnocientífica, que observa una parte de la realidad e ignora la otra porque no puede integrarla en sus esquemas. Pero los organismos generados por la biotecnología interactúan con otros que, para muchas otras culturas, pueden poseer otra simbolización. Si alguien puede considerar un delito talar o pintar un árbol, ¿cómo debiera considerarse entonces modificar el material genético?

Se asume que los organismos biotecnológicos conllevan riesgos elevados: las comisiones de bioseguridad son un buen ejemplo. Si no existiera el riesgo nadie crearía instituciones para velar por la seguridad. En Latinoamérica, ¿qué sentido tiene desarrollar o aceptar una tecnología que puede acarrear consecuencias globales sólo para responder a unos deseos minoritarios y, además, que ni siquiera satisfacen las necesidades del continente? El dilema beneficio-riesgo parece estar desplazado hacia el beneficio de una minoría y el riesgo para toda la humanidad.

\section{Autonomía}

La biotecnología genera una realidad que no todas las culturas pueden identificar, 1o que implica consensuar y trabajar con todas ellas para identificar estos nuevos objetos artificiales, si es que ellas desean acceder a esa tecnología. Se deben crear espacios para que esos pueblos y culturas que no quieran aceptar esta íntima modificación de su realidad no queden sujetas a los intereses de una parte de la humanidad. No es sólo una cuestión científica: la biotecnología genera una interrogante muy amplia en la cual la bioética debe crecer y no quedarse circunscrita a la ética clínica en la cual algunos quieren relegarla. La bioética debe florecer en su máxima expresión como ética que surge de un nuevo enfrentamiento con la realidad modificada tecnocientíficamente y en una de sus posibles esencias: su código genético.

En la era de la biotecnología no hay autonomía social para afrontar su desarrollo; unos intereses predominan y sólo hay una visión para afrontar el objeto biotecnológico: la visión científica. Es necesario que la bioética asuma el 
Animales transgénicos como organismos artificiales - A. Bota

reto de hacer dialogar a las diferentes comunidades, no aceptando como válidas a priori las posturas biotecnológicas, sino aceptando que las diferentes concepciones de la realidad son igualmente respetables.

La realidad natural seguirá siendo a los ojos de la humanidad la misma. Pero, seguramente, esto no será más que un engaño, ya que habrá sido íntimamente modificada por una parte minoritaria de la sociedad. Y el engaño, por ignorancia o desinformación, anula la posible autonomía de los sujetos, individual o colectivamente.

\section{Beneficencia}

Cualquiera tecnología desarrollada bajo un sistema de interacción universidad-empresa y protegida por un sistema de patentes en la órbita capitalista no persigue - directa o indirectamente- la beneficencia. Si, además, se expropia la biodiversidad protegida y identificada por otras culturas no puede pretender constituirse en una tecnología para el desarrollo de los países del sur. Otra visión sería que existiera una transferencia tecnológica norte-sur, como ha existido transferencia de germoplasma sur-norte, pero esto no sucederá. La transferencia tecnológica actual se podría clasificar de marginal, caritativa o destinada a generar más dependencia.

\section{Bibliografía}

Aristóteles. Obras Completas. Tratado del Alma. Buenos Aires: Anaconda; 1947.

Beauchamp T, Childress J. Principios de Ética Biomédica. Barcelona: Masson; 1999.

Duque F. Filosofía de la técnica de la naturaleza. Madrid: Tecnos; 1986.

Ellacuria I. Escritos filosóficos I. El Salvador: UCA; 1984.

Kant I. Crítica de la razón pura. Madrid: Alfaguara; 1978.

Lovelock J. Las edades de Gaia. Barcelona: Tusquets; 1993.

Ortega y Gasset J. Historia como sistema y otros ensayos de filosofía. Madrid; Alianza Editorial; 1999.

Ortega y Gasset J. Obras completas. XII vols. Reflexiones sobre la técnica. Madrid: Revista de Occidente; 1946-1983.

Singer P. Ética Práctica. Barcelona: Ariel; 1995.

Waghensberguer VVAA. El Progreso. Barcelona: Metatemas; 1997.

Zubiri X. Estructura dinámica de la realidad. Madrid: Alianza Editorial-Fundación Xavier Zubiri; 1989.

Zubiri X. Los problemas fundamentales de la metafísica occidental. Madrid: Alianza Editorial/Fundación Xavier Zubiri; 1994.

Zubiri X. Siete ensayos de antropología filosófica. Bogotá: Bogotá-Universidad de Santo Tomás; 1994.

Zubiri X. Sobre el hombre. Madrid: Alianza Editorial-Sociedad de Estudios y Publicaciones; 1986.

Recibido el 12 de noviembre de 2006.

Aceptado el 01 de marzo de 2007. 